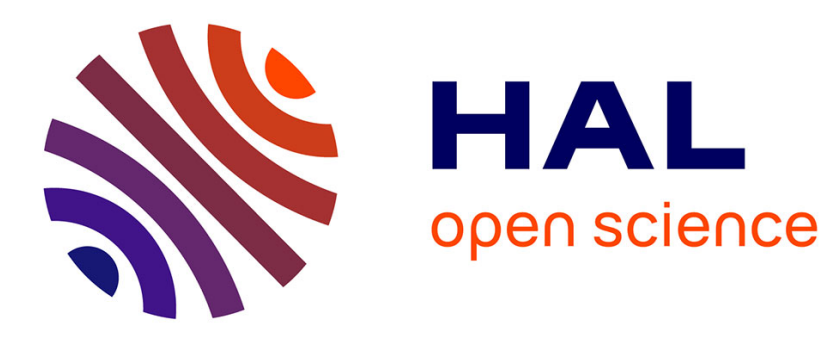

\title{
Les Matériaux Magnétiques pour l'Electronique Sous la Présidence de M. le Professeur Néel - Comptes Rendus de la Journée d'Etudes Orsay, mardi 12 mars 1974
} Jean-Marie Nicolas, G. Pircher

\section{To cite this version:}

Jean-Marie Nicolas, G. Pircher. Les Matériaux Magnétiques pour l'Electronique Sous la Présidence de M. le Professeur Néel - Comptes Rendus de la Journée d'Etudes Orsay, mardi 12 mars 1974. Revue de Physique Appliquée, 1974, 9 (5), pp.R1-R1. 10.1051/rphysap:01974009050R100 . jpa-00243862

HAL Id: jpa-00243862

https://hal.science/jpa-00243862

Submitted on 1 Jan 1974

HAL is a multi-disciplinary open access archive for the deposit and dissemination of scientific research documents, whether they are published or not. The documents may come from teaching and research institutions in France or abroad, or from public or private research centers.
L'archive ouverte pluridisciplinaire HAL, est destinée au dépôt et à la diffusion de documents scientifiques de niveau recherche, publiés ou non, émanant des établissements d'enseignement et de recherche français ou étrangers, des laboratoires publics ou privés. 


\title{
REVUE DE PHYSIQUE APPLIQUÉE
}

Supplément au * Journal de Physique *

\section{Les Matériaux Magnétiques pour l'Electronique}

\author{
Sous la Présidence de M. le Professeur NÉEL
}

\section{Comptes Rendus de la Journée d'Etudes}

\section{ORSAY, mardi 12 mars 1974}

\section{AVANT-PROPOS}

Le 12 mars 1974 a eu lieu à la Faculté d'Orsay sous la Présidence du Professeur Néel, Prix Nobel, une journée consacrée à des exposés sur les matériaux magnétiques vus sous l'angle universitaire et industriel. Cette journée a été organisée sous les auspices :

- de la Société Française de Physique,

- de la Société Française des électroniciens et électriciens,

- de l'IEEE.

Elle a permis la confrontation des points de vue très variés des chercheurs et des ingénieurs.

Ce numéro spécial est consacré aux textes de ces conférences.

Nous suggérons que des réunions semblables qui permettent de faire le point des recherches universitaires et des problèmes industriels soient organisées dans l'avenir par les principales équipes travaillant dans le domaine du magnétisme.

Les Organisateurs
J. NICOLAS
G. PIRCHER

Laboratoire Central TH-CSF. 